\title{
Comparison Between Alvarado Score and Paediatric Appendicitis Score in Diagnosing Acute Appendicitis in Children
}

\section{Bikesh Rajbhandari, Geha Raj Dahal and Rameshwar Prasad Pokharel}

Paediatric Surgery Unit, Department of General Surgery, Institute of Medicine, Tribhuvan University Teaching Hospital, Kathmandu, Nepal

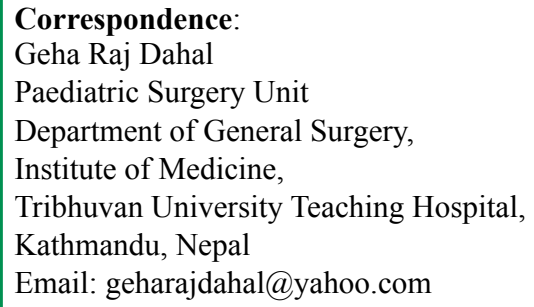

DOI: $10.3126 /$ jnps.v40i3.29288

Submitted on: 2020-06-05

Accepted on: 2020-10-10

Acknowledgements: We would like to express our gratitude to all children who were part of this study and acknowledge anesthetist colleagues and all other staffs involved

\section{Funding: Nil}

Conflict of Interest: None declared

Permission from IRB: Yes

To cite this article: Rajbhandari $B$, Dahal GR, Pokharel RP. Comparison between alvarado score and paediatric appendicitis score in diagnosing acute appendicitis in children. J Nepal Paediatr Soc. 2020;40(3):178-84.

\section{ABSTRACT}

Introduction: Acute appendicitis is the most common atraumatic surgical emergency in childhood. The accurate diagnosis of acute appendicitis is not always easy. Alvarado score (AS) and paediatric appendicitis score (PAS) are commonly used tools to assist diagnosis. This study compares the diagnostic accuracy between AS and PAS.

Methods: A prospective study was conducted from September 2016 to September 2017 in Paediatric Surgery Unit of Tribhuvan University Teaching Hospital. All eligible patients (children up to 16 years) who were operated for acute appendicitis were included. AS and PAS were calculated for all patients preoperatively. Final diagnosis of acute appendicitis was based on histopathological examination and labeled as 'appendicitis' or 'no appendicitis'. A cut off score of 7 for AS and 6 for PAS was compared with 'appendicitis' or 'no appendicitis' group.

Results: A total of 70 patients were included in the study. Sixty five (93\%) were histologically proven acute appendicitis and five (7\%) were no appendicitis. The sensitivity, specificity, PPV, NPV and accuracy of AS were $89 \%, 40 \%, 95 \%, 22 \%$ and $85 \%$ respectively. For PAS, sensitivity, specificity, PPV, NPV and accuracy was $97 \%, 40 \%, 95.5 \%, 50 \%$ and $92 \%$ respectively. On Receiver Operating Characteristic curve, 'area under curve' of AS was 0.64 and that of PAS was 0.84. It was not statistically significant $(\mathrm{p}=0.152)$.

Conclusions: There was no statistical significant difference between AS and PAS for diagnosing acute appendicitis.

Key words: Acute appendicitis; Alvarado score; Paediatric appendicitis score

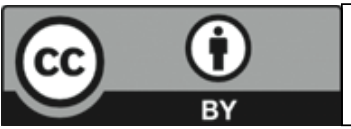

This work is licensed under creative common attribution 3.0 license 


\section{INTRODUCTION}

Appendicitis is the most common atraumatic surgical abdominal disorder in children. ${ }^{1}$ Atypical clinical findings are seen in $30 \%-50 \%$ of children, especially the younger ones which often leads to delayed diagnosis. ${ }^{2}$ Almost every abdominal pathology can be confused with acute appendicitis, especially in children. ${ }^{3}$ Delayed or missed diagnosis have the potential to result in significant morbidity from appendiceal perforation, abscess formation, wound infection, wound dehiscence and even mortality. ${ }^{4,5}$ However, negative diagnosis of acute appendicitis exposes children to unnecessary operation.

One of the most commonly used diagnostic score for diagnosis of acute appendicitis is the Alvarado Score (AS). This scoring system, created in 1986, was originally designed for adult population. ${ }^{6}$ Multiple studies have been conducted to validate the score for diagnosis in children. AS has high sensitivity and specificity so that it is applied for clinical practice throughout the world..$^{7-11}$

In 2002, Samuel developed the first appendicitis score that was specific to children. ${ }^{12}$ This paediatric appendicitis score (PAS) was developed by analyzing a cohort of 1170 children between four and 15 years of age. Sensitivity and specificity of PAS was higher than AS in children. This study was conducted to compare the diagnostic accuracy of AS and PAS in children in a tertiary hospital of Nepal.

\section{METHODS}

This was a prospective observational study conducted in Paediatric Surgery Unit of Tribhuvan University Teaching Hospital, Kathmandu, Nepal. The study was done over a period of one year from September 2016 to September 2017. Ethical approval was taken from Institutional Review Board of our institute. Informed consent was taken for every case from the legal guardian. All children up to 16 years, who were diagnosed as acute appendicitis and underwent appendectomy, were included in the study. Preoperative diagnosis of appendicular perforation peritonitis, appendicular lump and conservatively managed acute appendicitis were excluded. However, patients with local periappendiceal collection were included in the study.

The diagnosis of acute appendicitis was established clinically by surgeon on call in ER. Complete blood count $(\mathrm{CBC})$, renal function tests and routine urine examination were done in all patients. Ultrasonography (US) was done in patients as a routine diagnostic modality whenever feasible. US scan of abdomen was done to aid the diagnosis of acute appendicitis only. But analysis of US findings was not done.

The signs and symptoms components (migration of pain, anorexia, nausea, vomiting, fever, tenderness in right lower abdomen, rebound tenderness in right lower abdomen, pain on percussion, coughing, hopping) of AS (Table 1) and PAS (Table 2) were documented as present or absent. Other demographic variables of patients were noted. The decision to operate was based on clinical findings, lab investigations and US report and not affected by the study. The calculation of the AS and PAS score was done for study purpose only. For the study purpose the cut off point of 7 was used for AS and 6 for PAS as per Alvarado and Samuel., 612 Specimen of appendix from all patients were sent for histopathology examination (HPE). Final diagnosis of acute appendicitis was made by histological confirmation. Based on HPE report, patients were grouped as 'Appendicitis group' and 'No appendicitis group'. Comparison of AS of $\geq 7$ and $<7$ with 'Appendicitis group' and 'No appendicitis group' was done respectively. Similarly, comparison of PAS $\geq 6$ and $<6$ with the groups were done accordingly.

Statistical analysis was done by IBM SPSS (V. 24.0). Sensitivity, specificity, positive predictive value and negative predictive value with 95\% confidence interval (CI) was calculated for each score. A receiver operating characteristics (ROC) was created to assess the overall performance of scores. $\mathrm{P}$ value of $<0.05$ was considered as significant.

\section{RESULTS}

During the study period, 82 patients presented to emergency with acute appendicitis, among which 
Table 1. Alvarado score

$\begin{array}{lr}\text { Characteristics } & \text { Points } \\ \text { Migration of pain } & 1 \\ \text { Anorexia } & 1 \\ \text { Nausea/vomiting } & 1 \\ \text { Right lower quadrant tenderness } & 2 \\ \text { Rebound tenderness } & 1 \\ \text { Elevation of temperature } & 1 \\ \text { Leukocytosis ( } \geq 10,000 / \mathrm{Ul}) & 2 \\ \text { Polymorphonuclear neutrophilia } \geq 75 \% & 1 \\ \text { Total } & 10\end{array}$

12 patients were excluded for appendicular perforation peritonitis, appendicular lump and conservatively managed appendicitis. Seventy patients were included in the study. All had undergone appendectomy. Out of 70 patients, 65 (93\%) were confirmed for acute appendicitis by HPE and grouped as 'Appendicitis group'. Remaining five (7\%) patients were grouped as 'No appendicitis group'. Mean AS and PAS in appendicitis group and 'No appendicitis group' are shown in table 3 . Each score was significantly different between appendicitis and no appendicitis group.

To compare AS with HPE findings of 'Appendicitis' and 'No appendicitis', a cut off score seven was taken i.e. AS $\geq 7$ as appendicitis and AS $<7$ as no appendicitis. Out of 70 patients, $61(87 \%)$ patients had AS $\geq 7$ and $9(12 \%)$ patients had AS < 7 (Table 4).

On analysing Alvarado score against HPE findings, with 7 as cut off point, it showed sensitivity of

Table 3. Mean score in both groups

\begin{tabular}{|c|c|c|c|c|}
\hline $\begin{array}{l}\text { Name } \\
\text { of } \\
\text { Score }\end{array}$ & $\begin{array}{l}\text { Total } \\
\text { score }\end{array}$ & $\begin{array}{c}\text { Appendicitis } \\
\text { Group } \\
(\mathbf{n}=\mathbf{6 5})\end{array}$ & $\begin{array}{c}\text { No } \\
\text { Appendicitis } \\
\text { Group }(n=5)\end{array}$ & $\underset{\text { value }}{p}$ \\
\hline AS & $\begin{array}{l}8.09 \pm \\
1.45\end{array}$ & $8.18 \pm 1.42$ & $6.8 \pm 1.30$ & 0.039 \\
\hline PAS & $\begin{array}{l}8.31 \pm \\
1.39\end{array}$ & $8.48 \pm 1.21$ & $6.2 \pm 1.92$ & 0.001 \\
\hline
\end{tabular}

Table 2. Paediatric Appendicitis Score

\begin{tabular}{|lr|} 
Characteristics & Points \\
\hline Migration of pain & 1 \\
Anorexia & 1 \\
Nausea / vomiting & 1 \\
Right lower quadrant pain tenderness & 2 \\
Cough / hopping / percussion tenderness in & 2 \\
the right lower quadrant & 1 \\
Elevation of temperature & 1 \\
Leukocytosis $\geq 10,000 \mathrm{u} / \mathrm{L}$ & 1 \\
Polymorphonuclear neutrophilia $\geq 75 \%$ & 10 \\
Total &
\end{tabular}

$89.2 \%$, specificity of $40.0 \%$, PPV of $95.1 \%$, NPV of $22.2 \%$ and $85 \%$ accuracy.

Similarly to compare PAS with HPE findings of appendicitis and no appendicitis, a cut off score 6 was taken i.e. PAS $\geq 6$ as 'Appendicitis' group and PAS $<6$ as 'No appendicitis'. Out of 70 patients, 66 (94\%) patients had PAS $\geq 6$ and $4(6 \%)$ patients had PAS $<6$. (Table 5)

On analysing PAS against HPE findings, with six as cut off point, it showed sensitivity of $96.9 \%$, specificity of $40.0 \%$, PPV of $95.5 \%$, NPV of $50.0 \%$ and $92 \%$ accuracy.

Performance of AS and PAS scores was calculated using receiver operating characteristics (ROC) curve of as shown in figures 1 and figure 2. Area under the curve (AUC) of AS was 0.64 and PAS was 0.84 . AUC of PAS was better than AS, but P value of AUC for both scores was not significant ( $\mathrm{P}$ $=0.152)$.

Table 4. Comparison of Alvarado score with HPE findings

\begin{tabular}{|lrrr|}
\hline $\begin{array}{l}\text { Alvarado } \\
\text { score }\end{array}$ & $\begin{array}{l}\text { Appendicitis } \\
\text { group }\end{array}$ & $\begin{array}{l}\text { No appendicitis } \\
\text { group }\end{array}$ & Total \\
\hline$\geq 7$ & 58 & 3 & 61 \\
$<7$ & 7 & 2 & 9 \\
Total & 65 & 5 & 70 \\
\hline
\end{tabular}


Table 5. Comparison of PAS with HPE findings

\begin{tabular}{|lrrr|}
\hline PAS & $\begin{array}{c}\text { Appendicitis } \\
\text { group }\end{array}$ & $\begin{array}{c}\text { No appendicitis } \\
\text { group }\end{array}$ & Total \\
\hline$\geq 6$ & 63 & 3 & 66 \\
$<6$ & 2 & 2 & 4 \\
Total & 65 & 5 & 70 \\
\hline
\end{tabular}

\section{DISCUSSION}

Acute appendicitis is the commonest cause of acute abdominal pain in children. Typical clinical features of peri-umbilical pain, shifting to right lower abdomen, nausea, vomiting and fever are seen in less than $60 \%$ cases. $^{13}$ There are various causes of pain abdomen and many of them are quite confusing with acute appendicitis. Only about 1\% $8 \%$ of children with pain abdomen had actually acute appendicitis. ${ }^{14,15}$ Distinguishing appendicitis from other disorders is sometimes difficult, particularly in children.,16 Early and accurate diagnosis of acute appendicitis is essential to reduce the morbidity associated with delayed diagnosis and even mortality. On the other hand, over diagnosis may result in unnecessary appendectomies.

Numerous scoring systems for diagnosing acute appendicitis have been designed to make accurate diagnosis. Alvarado in 1986 designed a score with eight predictive factors and a maximum of 10 scores. ${ }^{6}$ In his study, he recommended that patients with AS less than five to discharge as no appendicitis, those with $5-6$ to keep under observation as possible appendicitis, and those with seven or higher to operate as likely appendicitis. Alvarado originally designed it for adult population. Later different researchers have conducted studies to evaluate AS in children. One of the notable works was done by Schneider et al. They showed a sensitivity of $81 \%$, specificity of $74 \%$, PPV of $92 \%$, and NPV of $46 \%$ when evaluated patients up to 21 years. ${ }^{11}$ When analysis was done taking population of less than 10 years only, the accuracy was less. Overall accuracy of AS ranged from $60-86 \%$ in different literatures. $7,8,17,18$

In our study, however we had sensitivity of $89.2 \%$, specificity of $40.0 \%$, PPV of $95.1 \%$, NPV of $22.2 \%$

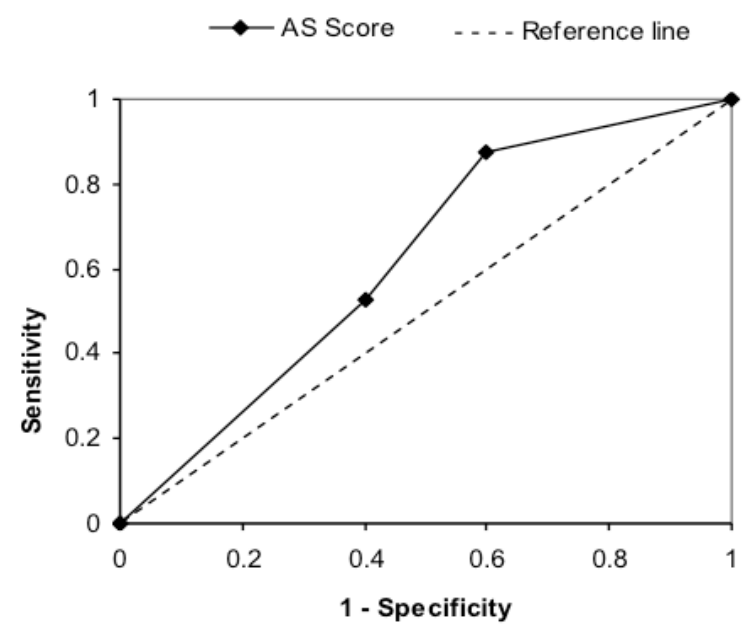

Figure 1. ROC curve of Alvarado score in diagnosing acute appendicitis

and accuracy of $85 \%$ of AS. We had low specificity and NPV because three patients (4.2\%) with AS $\geq 7$ had normal appendix on HPE and seven patients $(10 \%)$ with Alvarado score $<7$ had inflamed appendix on HPE respectively.

In modified Alvarado Score, left shift of leucocytosis is omitted and total score is nine. This score seems more accurate than original AS in children in a study by Peyvasteh et al. ${ }^{19}$ Ultrasound can be combined with AS to exclude appendicitis. A negative predictive value of $99.6 \%$ of this combination tool was demonstrated by Blitman et al. ${ }^{20}$

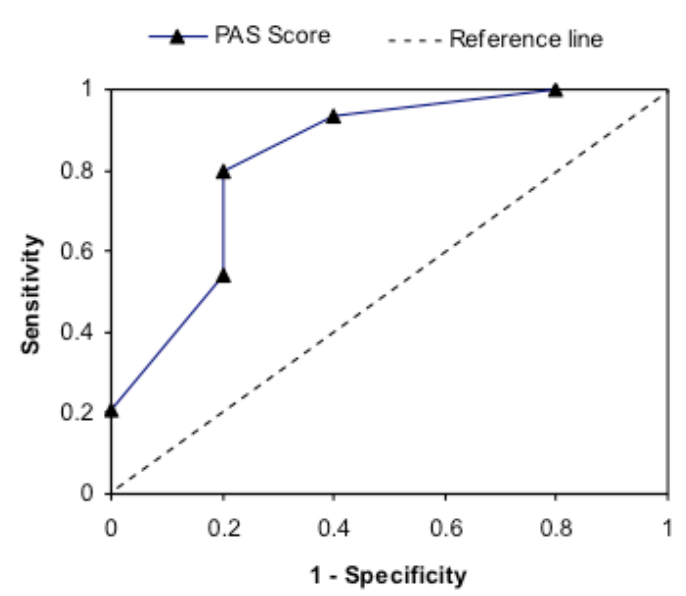

Figure 1. ROC curve of Alvarado score in diagnosing acute appendicitis 
In 2002, Samuel designed a specific score for children through a prospective sample of 1170 patients from four to 15 years over a period of five years. ${ }^{12}$ This PAS is a modification of AS and carries a maximum of 10 scores. The recommendations of his article were that patients with PAS $\leq 5$ do not have appendicitis, whereas those with $\geq 6$ should be operated on under suspicion of appendicitis. In his study, the sensitivity was $100 \%$, specificity was $92 \%$, PPV was $96 \%$, and NPV was $99 \%$. His work has been reproduced by many authors and found variable results. The overall sensitivity and specificity ranges $72 \%-100 \%$ and $50 \%-94 \%$ and accuracy of $72 \%-97 \% .{ }^{12,21-23}$

In our study, PAS had sensitivity of $96.9 \%$, specificity of $40.0 \%$, PPV of $95.5 \%$, NPV of $50.0 \%$ and accuracy of $92 \%$. Our study had similar results in sensitivity and PPV but has a low specificity and NPV. We didn't find adequate specificity and NPV because, three patients (4.2\%) with PAS $\geq 6$ had normal appendix on HPE and two patients $(2.8 \%)$ with PAS $<6$ had inflamed appendix on HPE respectively.

$\mathrm{Wu} \mathrm{H}$ et al. in 2011, compared AS and PAS according to the duration of symptoms. The best cut off value varied six to seven on days one, two and three of symptom duration for both AS and PAS. There was no specific trend regarding duration of symptoms and cut off values. ${ }^{24}$ When PAS is supplemented by US scan of abdomen, the diagnostic yield increases. PAS $>4$ with positive ultrasound showed a sensitivity of $96.3 \%$, specificity of $94.1 \%$, PPV of $96.1 \%$ and NPV of $94.1 \%{ }^{25}$ Low dose of CT scan has more diagnostic accuracy but it cannot be used routinely. Combination of PAS and USG was also suggested by Sayed et al. ${ }^{26}$

Pogorelic et al., in their study of comparison of these scoring systems for acute appendicitis, found that both scores do not have adequate predictive value. They suggested that it can be used only as assistance for clinical judgment for a clinician. ${ }^{10}$ We didn't find significant difference between the performance of the two scoring system ( $p$ value of AUC was 0.152). The same conclusion was reached in a prospective study carried out by Schneider et al on 588 patients. AUC in ROC curve for AS and PAS was 0.83 and 0.81 respectively with no significant difference. ${ }^{11}$ Mecco et al. conducted a study to compare the performance of scores including appendicitis inflammatory response score along with AS and PAS. AUC of appendicitis inflammatory response score was 0.90 better than AS (AUC $=0.87)$ and PAS $(\mathrm{AUC}=$ $0.82) .27$

The original intent of both the Samuel and Alvarado was to determine operative care based on specific score value, therefore PPV has the most relevance to the clinician. Our study had a PPV of $95.1 \%$ and $95.5 \%$ for Alvarado and PAS, signifying a higher probability of having acute appendicitis in those patient having positive test results with resulting less negative appendectomies. However, neither the PAS nor the AS had an adequate negative predictive value in the diagnosis of acute appendicitis. The negative predictive value obtained in our study was not sufficient enough to label somebody as not having acute appendicitis when the score was below the cut off label.

\section{CONCLUSIONS}

There is no difference between the Alvarado score and PAS for diagnosing acute appendicitis, although sensitivity and NPV of PAS is better than AS. Since the specificity and NPV was low for both scores, acute appendicitis in children cannot be excluded based on these scores. 


\section{REFERENCES}

1. Reynolds SL, Jaffe DM. Diagnosing abdominal pain in a pediatric emergency department. Pediatr Emerg Care. 1992;8(3):126-8. DOI: 10.1097/00006565-199206000-00003

2. Rosendahl K, Aukland SM, Fosse K. Imaging strategies in children with suspected appendicitis. Eur Radiol Suppl. 2004;14(4):138-45. DOI: 10.1007/s00330-003-2077-3

3. Dahal GR. Acute appendicitis in children: How is it different than in adults?. Grande Med J. 2019;1(1):35-40. DOI: 10.3126/gmj.v1i1.22404

4. Eldar S, Nash E, Sabo E, Matter I, Kunin J, Mogilner JG, et al. Delay of surgery in acute appendicitis. Am J Surg. 1997;173(3):194-8. DOI: 10.1016/S0002-9610(96)00011-6

5. Koepsell TD, Inui T, Farewell VT. Factors affecting perforation in acute appendicitis. Surg Gynecol Obstet. 1981;153(4):508-10. PMID: 7280938

6. Alvarado A. A practical score for the early diagnosis of acute appendicitis. Ann Emerg Med. 1986;15(5):557-64. DOI: $10.1016 / \mathrm{s} 0196-0644(86) 80993-3$

7. Bond GR, Tully SB, Chan LS, Bradley RL. Use of the MANTRELS score in childhood appendicitis: a prospective study of 187 children with abdominal pain. Ann Emerg Med. 1990;19(9):1014-8. DOI: 10.1016/ S0196-0644(05)82566-1

8. Macklin CP, Radcliffe GS, Merei JM, Stringer MD. A prospective evaluation of the modified Alvarado score for acute appendicitis in children. Ann R Coll Surg Eng. 1997;79(3):203. PMID: PMC2502889

9. Escribá A, Gamell AM, Fernández Y, Quintillá JM, Cubells CL. Prospective validation of two systems of classification for the diagnosis of acute appendicitis. Pediatr Emerg Care. 2011;27(3):165-9. DOI: 10.1097/PEC. 0b013e31820d6460

10. Pogorelic Z, Rak S, Mrklic I, Juric I. Prospective validation of Alvarado score and Pediatric Appendicitis Score for the diagnosis of acute appendicitis in children. Pediatr Emerg Care. 2015;31(3):164-8. DOI: 10.1097/PEC. 0000000000000375

11. Schneider C, Kharbanda A, Bachur R. Evaluating appendicitis scoring systems using a prospective pediatric cohort. Ann Emerg Med. 2007;49(6):778-84. DOI: 10.1016/j.annemergmed.2006.12.016

12. Samuel M. Pediatric appendicitis score. J Pediatr Surg. 2002;37(6):877-81. DOI: 10.1053/jpsu.2002.32893

13. Rothrock SG, Pagane J. Acute appendicitis in children: emergency department diagnosis and management. Ann Emerg Med. 2000;36(1):39-51. DOI: 10.1067/mem.2000.105658

14. Alloo J, Gerstle T, Shilyansky J, Ein SH. Appendicitis in children less than 3 years of age: a 28 -year review. Pediatr Surg Int. 2004;19(12):777-9. DOI: 10.1007/s00383-002-0775-6.

15. Caperell K, Pitetti R, Cross KP. Race and acute abdominal pain in a pediatric emergency department. Pediatr. 2013;131(6):1098-106. DOI: 10.1542/peds.2012-3672

16. Toorenvliet B, Vellekoop A, Bakker R, Wiersma F, Mertens B, Merkus J, et al. Clinical differentiation between acute appendicitis and acute mesenteric lymphadenitis in children. Eur J Pediatr Surg. 2011;21(02):120-3. DOI: $10.1055 / \mathrm{s}-0030-1267979$

17. Hsiao 2005 Hsiao KH, Lin LH, Chen DF. Application of the MANTRELS scoring system in the diagnosis of acute appendicitis in children. Acta Paediatr Taiwan. 2005;46(3):128-31. PMID: 16231558

18. Chong CF, Thien A, Mackie AJ, Tin AS, Tripathi S, Ahmad MA, Tan LT, Ang SH, Telisinghe PU. Comparison of RIPASA and Alvarado scores for the diagnosis of acute appendicitis. Singapore Med J. 2011;52(5):340-5. PMID: 21633767

19. Peyvasteh M, Askarpour S, Javaherizadeh H, Besharati S. Modified Alvarado score in children with diagnosis of appendicitis. Arq Bras Cir Dig. 2017;30(1):51-2. DOI: 10.1590/0102-6720201700010014

20. Blitman NM, Anwar M, Brady KB, Taragin BH, Freeman K. Value of focused appendicitis ultrasound and alvarado score in predicting appendicitis in children: can we reduce the use of CT?. AJR Am J Roentgenol. 2015;204(6): 707-12. DOI: 10.2214/AJR.14.13212 
21. Goulder F, Simpson T. Pediatric appendicitis score: A retrospective analysis. J Indian Assoc Pediatr Surg. 2008;13(4):125. DOI: 10.4103/0971-9261.44761

22. Goldman RD, Carter S, Stephens D, Antoon R, Mounstephen W, Langer JC. Prospective validation of the paediatric appendicitis score. J Pediatr. 2008;153(2):278-82. DOI: 10.1016/j.jpeds.2008.01.033

23. Adibe OO, Muensterer OJ, Georgeson KE, Harmon CM. Severity of appendicitis correlates with the pediatric appendicitis score. Pediatr Surg Int. 2011;27(6):655-8. DOI: 10.1007/s00383-010-2744-9

24. Wu HP, Yang WC, Wu KH, Chen CY, Fu YC. Diagnosing appendicitis at different time points in children with right lower quadrant pain: comparison between Pediatric Appendicitis Score and the Alvarado score. World J Surg. 2012;36(1):216-21. DOI: 10.1007/s00268-011-1310-5

25. Planella MC, Pociello NA, Domingo AR, Bringue XE, Rue MM, Sole EM. Utility of Pediatric Appendicitis Score and abdominal ultrasound in the diagnostic process of acute appendicitis. Cir Pediatr. 2019;32(3):128-34. PMID: 31486304

26. Sayed AO, Zeidan NS, Fahmy DM, Ibrahim HA. Diagnostic reliability of pediatric appendicitis score, ultrasound and low-dose computed tomography scan in children with suspected acute appendicitis. Ther Clin Risk Manag. 2017;13:847. DOI: 10.2147/TCRM.S134153

27. Macco S, Vrouenraets BC, de Castro SM. Evaluation of scoring systems in predicting acute appendicitis in children. Surgery. 2016;160(6):1599-604. DOI: 10.1016/j.surg.2016.06.023 